\title{
Comparative Study of ZigBee and 6LoWPAN Protocols: Review
}

\author{
I. Alaoui Ismaili ${ }^{1}$, A. Azyat ${ }^{2}$, N.Raissouni ${ }^{3}$, N. Ben Achhab ${ }^{4}$, A. Chahboun ${ }^{5}$, M.Lahraoua ${ }^{6}$ \\ iuoala.imane@gmail.com ${ }^{1}$ \\ azyat2037@gmail.com² \\ naoufal.raissouni.ensa@gmail.com ${ }^{3}$
}

Abdelmalek Essaadi University, Tetouan, Morocco $^{1}$

National School of Applied Sciences of Tangier, Morocco ${ }^{2}$

National School of Applied Sciences of Tetouan, Morocco ${ }^{3}$

\begin{abstract}
Several types of research have been made on short-range and low-level wireless networks energy consumption since their appearances until today. To examine the specificities of each, we have done a comparative study to highlight the strengths and weaknesses based on energy consumption, scope and reliability of mesh architecture to conclude open international standard, and more adapted to industrial needs. This paper addresses the low power mechanisms provided by 6LoWPAN and the ZigBee Protocol with their two version (ZigBee-Pro and ZigBee IP), providing comparative assessments based on the results obtained by available in specialized literature and different researchers. The results show that ZigBee IP can be the most appropriate protocol in case we want to connect multiple nodes with fast communication and optimized power consumption
\end{abstract}

Keywords: 6LoWPAN, ZigBee, ZigBee-Pro and ZigBee IP

\section{Introduction}

The Internet of Things (IoT) is considered to be the next big challenge for the communication research community. It deployed two main categories of networks: short-range low power networks (called last 100 meters of connectivity) and long-range low power networks (called Low-Power Wide Area Networks (LPWAN)). Both short-range and long-range low power networks will play a crucial role in the IoT world where each network type has its unique applications and characteristics [23]. This paper has focused on a comparative study of two short range wireless protocols such as ZigBee and 6LoWPAN in terms of energy consumption, scope and reliability.

Several researches have been made on short-range and low-level wireless networks energy consumption since their appearances until today. For better understand the specifics of standard including ZigBee and 6LoWPAN. The comparison we made in this study does not value one of the technologies discussed, but mostly helps engineers in the design of new wireless network applications. We have presented a state of the art in research and development of architecture and topology of ZigBee and 6LoWPAN. We also proposed a simple study comparing between the ZigBee, ZigBee IP, ZigBee-Pro and 6LoWPAN protocols by considering the criteria of modulation type, network, topology, power, range, cryptography, spreading and coexistence

The paper is organized as follows. First part outlines related works while Second part describes the two (ZigBee and 6LoWPAN) protocols with a focus on their architecture and topology. The third part shows the experimental results and comparison between the ZigBee standard, ZigBee IP and 6LoWPAN while the last part provides our conclusions

\section{Related works}

Recently, many papers review, compare and evaluate ZigBee and 6LoWPAN with other wireless technologies. In [1], Lee, Su, \& Shen in the study of the most used wireless networks (Bluetooth, UWB, ZigBee and $\mathrm{Wi}-\mathrm{Fi}$ ), they evaluated the main characteristics and behaviors in terms of various measures, including the efficiency of data coding, the delay of transmission, complexity of operation and energy consumption. They came up with results that claim that ZigBee is taking more time compared to others but still the better suited solution for mobile applications of battery-operated wireless sensor networks. In [2], Baker has done comparative study to highlight the strengths and weaknesses of ZigBee and Bluetooth in industrial applications by certifying that the ZigBee standard based on IEEE802.15.4 is more efficient in terms of power consumption, reliability and scope. They conclude that ZigBee is intended to be an open international standard, more adapted to industrial needs. In 
[3], Vinay Kumar \& Sudarshan Tiwari was done on the different routing algorithm and IP mobility in 6LoWPAN and comparing the basis of different metric like energy consumption, memory uses, mobility, scalability, and so forth. It was found that the routing protocols have their own advantages depending upon the application where they are used. Hi-Low routing protocol provides an advantage of memory saving by which the networks become more scalable. DYMO-Low provides more routing delay compared to other routing protocols. S-AODV provides benefits in terms of traffic reduction, power consumption, and network lifetime extension, for 6LoWPAN. In [4], Mazzer \& Tourancheau compared the different implementations of 6LoWPAN on WSN and showcased the wireless technology that has become the primary means of communication for sensor networks. To overcome the problems of conforming to current standards and ensure the accessibility of nodes sensors the 6LoWPAN protocol was designed. In [4], Toscano \& Lo discusses the adaptation of the 6LoWPAN protocol and mechanisms of the ZigBee standard to operate at low power. Generally, these mechanisms put nodes on standby to reduce the service cycle. Although both technologies are based on same lower layers, but the ZigBee approach is quite different from that adopted by 6LoWPAN. 6LoWPAN protocol based on 1Pv6 is asynchronous, requires channel listening mechanisms (for power saving purposes) because it does not support sleeper nodes and adopts a mesh topology. ZigBee defines the beacon mode that allows nodes to stay in low power mode for most of the time and periodically sends nodes a sync tag through the use of tree routing. In [4] they tried to make a comparative study between three wireless short-range wireless protocols, Bluetooth and ZigBee to deploy a wireless sensor network. The main intention of their study is to find the most appropriate protocol applicable to wireless sensor networks. In This study analyzed 3 protocols based on a transmission time, rate of bit error, signal strength received, and packet delivery ration and energy consumption. Thus, can we conclude that ZigBee is the best protocol among the three protocols studied, ZigBee has a stable transmission time, better spectral efficiency, a higher packet transmission ratio and minimal power consumption. In [5], Lucia Lo Bello in the study of the performance of 6LoWPAN and ZigBee protocols for high speed industrial networks. The results of the experimental evaluations showed that the ZigBee network is capable of handling shorter run cycles, generating maximum end-to-end delays and update times slightly below the theoretical values of 6LowPAN. On the other hand, the 6LoWPAN network has medium end-to-end delays and higher reliability (a lower percentage of packet loss). In [6], Franceschinis \& al are tried to compare the two piles of ZigBee-Pro protocol and ZigBee IP developed in order to integrate ZigBee into the Internet of Things

\section{Network Architecture}

This section will give a thorough description for network architecture of ZigBee and 6LoWPAN. Commonly, the layers or architecture and topologies.

\subsection{ZigBee}

The ZigBee network (IEEE802.15.4) provides high-level wireless data transmission for the purpose of communicating small devices over radio links. It was created to be a standard for low-cost, high-level communication protocols and will be used in applications that require secure network devices, low data throughput, and longer battery life. ZigBee can support different types of topologies, such as mesh, star, and tree network topologies.

The architecture of the ZigBee standard is composed of 4 layers: physical, MAC, network and application as shown in Fig. 1:

$*$

Physical layer translates sent and received frames into bits and manages the use of radio transmission and channel communication. The standard provides for two different physical layers (one for $868 / 915 \mathrm{MHz}$ and one for $2.4 \mathrm{GHz}$ ) using discrete sequence spread spectrum OQPSK (DSSS) modulation.

$*$

MAC layer: synchronizes the network and ensures the reliability of communications using CRC and retransmissions, manages the transmission of frames and reserved time slots, and controls

$*$ access to the wireless medium

ZigBee layer: provides routing, sends / receives data to and from the application layer, addresses nodes, builds and maintains network topology, and provides security.

\section{$*$}

Application Layer: Determines how all other layers behave. It is associated with several modules such as:

- Security Service Provider which manages security functions

- Application Sub-Layer support that supports the linking of devices

- ZigBee Device Object messaging services that enable discovery of devices 


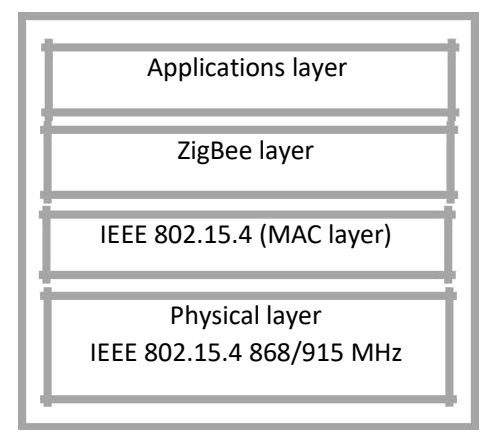

Fig. 1. ZigBee standard architecture

ZigBee includes the complete physical layer, the IEEE802.15.4 MAC specification for personal wireless networks, and other standard layers added based on the version of the ZigBee network used, such as ZigBee Pro and ZigBee IP.

\subsubsection{ZigBee Pro}

The ZigBee-Pro version is a significant enhancement to the ZigBee standard and advanced support for large networks of many nodes. ZigBee-Pro enables the transmission of large messages using fragmentation and reassembly and uses a gateway for data transfer from ZigBee nodes to the Internet. ZigBee-Pro is based on a mesh topology and not beacon mode. The main feature of this version is present in the table [7] below

Table 1. Features of ZigBee-PRO [7]

\begin{tabular}{|c|c|}
\hline Features & Comments \\
\hline Addressing & $\begin{array}{l}\text { The new devices that add up to the network will automatically have an address and if two } \\
\text { nodes have the same address, the network layer intervenes based on the MAC address of each } \\
\text { node. }\end{array}$ \\
\hline Links management & Each node of the mesh topology is able to communicate with its neighbor \\
\hline Changed channel & $\begin{array}{l}\text { The channel manager selects a new channel and notifies the rest of the network multiple } \\
\text { ZigBee nodes detect overlap or noise interference Channel change }\end{array}$ \\
\hline Fragmentation & $\begin{array}{l}\text { ZigBee-Pro provides the fragmentation of larger packets into smaller ones to facilitate } \\
\text { sending. }\end{array}$ \\
\hline $\begin{array}{l}\text { Power } \\
\text { Management }\end{array}$ & $\begin{array}{l}\text { Put devices in sleep mode to consume less power (When they wake up, they update } \\
\text { themselves in the case of a change in the network) }\end{array}$ \\
\hline Routing & ZigBee-Pro offers two types of routing multicast and many-ta-one. \\
\hline Security & There are two security modes in ZigBee-Pro: Standard Mode and Superior Security Mode \\
\hline
\end{tabular}

The architecture of ZigBee-Pro as Franceschinis and al defined in 2013 is as follows 


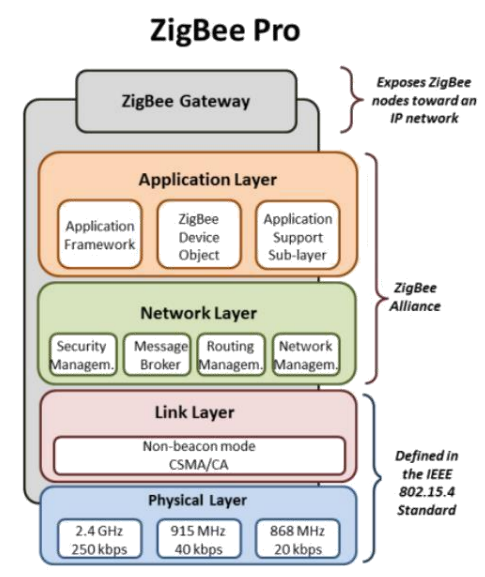

Fig. 2. ZigBee Pro network architecture [6]

\subsubsection{ZigBee IP}

ZigBee IP is for low-speed, short-range wireless mesh networks that support IPv6. It ensures the establishment of Internet connections seamlessly with low power and low-cost devices

ZigBee IP is based on the physical and MAC layers of the IEEE802.15.4 standard and improves network and application layers as recommended by the Internet Engineering Task Force. It provides end-to-end IPv6 networking without the use of intermediate gateways, uses standard protocols such as IPv6, 6LoWPAN, RPL, TCPIUDP and provides security through Transport Layer protocol. Figure 3 shows the protocols used at each layer of the ZigBee IP architecture. The physical and Link layers are based on IEEE 802.15.4 in the 2.4 GHz band. The NWK layer includes the RPL, IPv6, ICMP protocols. RPL is associated with 6LowPAN, the adaptation layer for the exchange of IPv6 packets on an IEEE 802.15.4-based network. TRN layer may adopt either TCP that is required to support HTTP or UDP that is optional to support CoAP

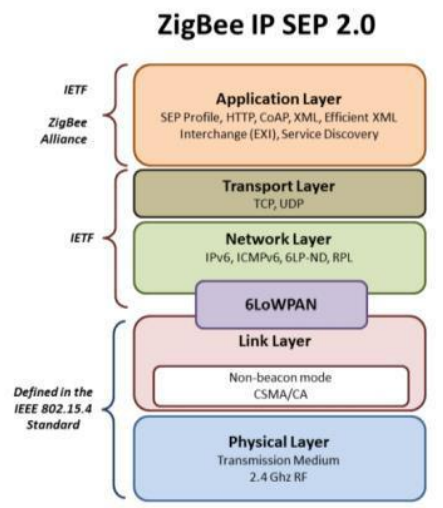

Fig.3. ZigBee IP network architecture [6] 


\subsection{LoWPAN}

The IPv6 over low-power wireless (6LoWPAN) is the short-range, low-power and personal area networks. It can be connected directly to another IP network without intermediate entities (gateways). The connection between 6LoWPAN elements is implemented via IEEE 802.15.4. It supports different lengths of addresses. It is also low bandwidth and low-cost power consumption. 6LoWPAN can support different types of topologies, such as mesh and star topologies.

The architecture of the 6LoWPAN is composed of 3 layers: host node, router node and edge router as shown in Fig. 2:

* Host node sense the physical environment and can actuated devices

* Router node Transfer data packets from hosts to edge routers or to a 6LoWPAN network destination. The connection between 6LoWPAN elements is implemented via IPv6 over IEEE 802.15.4.

* Edge router provide interconnection between the 6LoWPAN network and other IP networks. Sending and receiving packets between 6LoWPAN elements and IP nodes of other networks. Each 6LoWPAN element is identified by a unique IPv6 address.

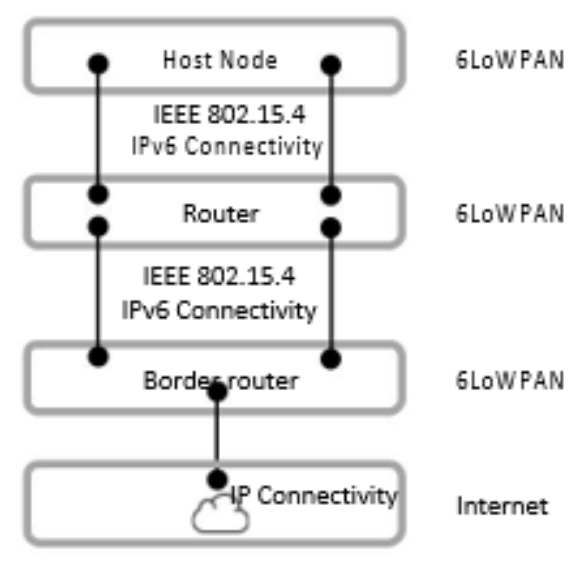

Fig.4. 6LLoWPAN architecture

Sending packets in a 6LoWPAN topology begins with the RFD endpoint that routes the same packet to an FFD router node that forwards, hopped the packet to the 6LoWPAN gateway. This gateway that is connected to the internet with the 1Pv6 domain will then forward the packet to its destination using the IP protocol. 


\section{Comparative study}

This section, present different criteria are used to benchmark the differences between the ZigBee, ZigBee IP, ZigBee-Pro and 6LoWPAN protocols. Such criteria include standard, modulation type, network, topology, power, range, cryptography, spreading and coexistence

\subsection{ZigBee-Pro and ZigBee IP}

In [21], I. BERDAI compared the results of the third topology of the ZigBee-Pro network obtained with the XBee devices with the results of the first topology of the ZigBee IP developed on Contiki. For ZigBee-Pro, she emulated with real hardware and ZigBee IP was simulated virtually using Contiki. Table 1 shows the simulation results

Table 2. Comparison of results between ZigBee-Pro and ZigBee IP [22]

\begin{tabular}{lll}
\hline & ZigBee-Pro & ZigBee IP \\
\hline Delay & $213.073 \mathrm{~ms}$ & $127 \mathrm{~ms}$ \\
Energy & $0.00031 \mathrm{~J}$ & $2,28 \times$ lo-s J \\
\hline
\end{tabular}

Test results shows that ZigBee-Pro, takes more time and more energy. On the other hand, data exchange for ZigBee IP is faster and energy consumption has been optimized. This is due to the use of advanced mechanisms like IPv6, 6LoWPAN

\subsection{ZigBee and 6LoWPAN}

The comparative study of ZigBee standard and 6LoWPAN reveals that 6LoWPAN adds IP functionality to WPANs and consumes little power, while ZigBee supports many more nodes operates at low power and requires a low cost. ZigBee can be used in HAN networks, as well as for smart metering, if it is used in a mesh structure. It can also provide remote intelligent meter monitoring and other devices. ZigBee has reliable security and uses powerful encryption techniques. It has a networking technique far superior to that of other technologies that avoids the collision of channels. On the other hand, 6LoWPAN is suitable for IP-based low power devices such as sensors and controllers. The main attributes of these technologies have been summarized in Table 2. In terms of power consumption, 6LoWPAN and ZigBee are designed for portable devices and limited battery power. Thus, it offers low power consumption. In the context of the comparison between ZigBee IP and 6LoWPAN, ZigBee IP is considered the first open standard of ZigBee compatible with IPv6 protocol. It provides seamless connection with low-power, low-cost devices. The 6LoWPAN adaptation layer built into ZigBee IP ensures interoperability between the link layer defined by the 802.15.4 standard and the network layer that supports IPv6, this is to bind any which device to the internet. 
Table 3. Comparison between the 6LoWPAN and ZigBee

\begin{tabular}{|c|c|c|c|}
\hline & $\begin{array}{l}\text { 6LoWPAN } \\
{[6],[18],[20],[8]}\end{array}$ & $\begin{array}{l}\text { ZigBee } \\
{[18],[6],[21],[8]}\end{array}$ & $\begin{array}{l}\text { ZigBee IP } \\
\text { [9], [10], [12-20] }\end{array}$ \\
\hline Radio Frequency & $\begin{array}{c}868 \mathrm{MHz}, 915 \mathrm{MHz}, \\
2,4 \mathrm{GHZ}\end{array}$ & $\begin{array}{c}868 \mathrm{MHz}, 915 \mathrm{MHz}, \\
2,4 \mathrm{GHZ}\end{array}$ & $\begin{array}{c}868 \mathrm{MHz}, 915 \mathrm{MHz}, \\
2,4 \mathrm{GHZ}\end{array}$ \\
\hline RF Data Rate & $250 \mathrm{Kbps}$ & $250 \mathrm{Kbps}$ & $250 \mathrm{Kbps}$ \\
\hline Peak Current & $\mathrm{Rx} 20-35 \mathrm{~mA}$ & $\mathrm{Rx} 20-35 \mathrm{~mA}$ & \\
\hline Consumption & Tx $12-25 \mathrm{~mA}$ & Tx 20-30 mA & \\
\hline Network Topology & Star or Mesh & mesh, star & Cluster tree, Mesh \\
\hline $\begin{array}{l}\text { Suitable for } \\
\text { WBANs }\end{array}$ & $\begin{array}{l}\text { Suitable for application } \\
\text { with low data rate and } \\
\text { on-body sensors }\end{array}$ & portable devices & $\begin{array}{l}\text { portable devices and for } \\
\text { application with low data } \\
\text { rate and on-body sensors }\end{array}$ \\
\hline $\begin{array}{l}\text { Max Outdoor } \\
\text { Range }\end{array}$ & $10-200$ meters & 500 meters & $10-1000$ \\
\hline Security & $\begin{array}{c}\text { 128b AES and } \\
\text { application layer user } \\
\text { defined }\end{array}$ & AES & $\begin{array}{l}\text { AES block cipher (CTR, } \\
\text { counter mode) }\end{array}$ \\
\hline Max Nodes & 100 & 65,536 & $>65000$ \\
\hline Standard & IEEE 802.15 .4 & IEEE802.15.4 & IEEE802.15.4 \\
\hline $\begin{array}{l}\text { Common } \\
\text { Applications }\end{array}$ & $\begin{array}{l}\text { Monitor and Control } \\
\text { via internet }\end{array}$ & $\begin{array}{l}\text { Home industry } \\
\text { monitoring and } \\
\text { controlling }\end{array}$ & $\begin{array}{c}\text {,Monitor and Control via } \\
\text { internet }\end{array}$ \\
\hline $\begin{array}{l}\text { Mesh Network } \\
\text { Support }\end{array}$ & Many & Zigbee & Many \\
\hline Internet & Bridge/Router & Zigbee Gateway & Zigbee Gateway/ \\
\hline $\begin{array}{l}\text { Connectivity } \\
\text { RF Radio Support } \\
\text { Network Size }\end{array}$ & 802.15.4 & $\begin{array}{c}802.15 .4 \\
65 \mathrm{~K}\end{array}$ & $\begin{array}{l}\text { Bridge/Router } \\
802.15 .4\end{array}$ \\
\hline $\begin{array}{l}\text { Header Overhead } \\
\text { Code Size with } \\
\text { mesh }\end{array}$ & $\begin{array}{c}2-11 \text { bytes } \\
22 \mathrm{~K}\end{array}$ & $\begin{array}{l}8-16 \text { bytes } \\
32 \mathrm{~K} \text { to } 64 \mathrm{~K}+\end{array}$ & \\
\hline
\end{tabular}

\section{Conclusion}

This paper presented state-of-the-art in research and development of architecture and topology of ZigBee and 6LoWPAN. The intension of this paper is not to draw any conclusion regarding which one is superior to others but to find the most appropriate protocol applicable for wireless sensor networks. In our work we have analyzed and compared ZigBee, ZigBee IP and 6LoWPAN protocols based on Network Topology, Max Outdoor Range, Security, and Max Nodes. According to our analysis we can conclude that ZigBee IP is the best protocol among those 3 as it has stable transmission time, lowest power consumption, highest packet delivery ratio, can bind any which device to the internet and have the Max Outdoor Range. 


\section{References}

[1] Lee, J. S., Su, Y. W., \& Shen "A comparative study of wireless protocols: Bluetooth, UWB, ZigBee, and Wi-Fi. IECON Proceedings” (Industrial Electronics Conference), 46-51. ttp://doi.org/10.1109/IECON.2007.4460126

[2] Baker "ZigBee and Bluetooth: strengths and weaknesses for industrial applications" Computing and Control Engineering, 16(2), 20-25. http:/ /doi.org/1 0.1 049/cce: 20050204

[3] Mazzer, Y., \& Tourancheau" Comparisons of6LoWPAN implementations on wireless sensor networks". Proceedings -2009 3rd International Conference on Sensor Technologies and

[4] Toscano, E., \& Lo Bello, L “Comparative assessments of IEEE 802.15.4/ZigBee and 6LoWPAN for law-power industrial WSNs in realistic scenarios" In 2012 9th IEEE International Workshop on Factory Communication Systems (pp. 115-124). IEEE. http://doi.org/10.1109/WFCS.2012.6242553

[5] Emanuele Toscano and Lucia Lo Bello "Comparative assessments of IEEE 802.15.4/ZigBee and 6LoWPAN for lowpower industrial WSNs in realistic scenarios" https://www.researchgate.net/publication/261203734, 22 October 2016

[6] Md. Taslim Arefin, Mohammad Hanif Ali, A.K.M. Fazlul Haque "A Comparative Analysis of Short Range Wireless Protocols For Wireless Sensor Network "International Journal of Scientific \& Engineering Research, Volume 8, Issue 4, April-2017

[7] Mirko Franceschinis, Claudio Pastrone, Maurizio A. Spirito "On the Performance of ZigBee Pro and ZigBee IP in IEEE 802.15.4 Networks” 2013 IEEE 9th International Conference on Wireless and Mobile Computing, Networking and Communications (WiMob)

[8] G. Mulligan. The 6LoWPAN architecture. In Proceedings of the 4th workshop on embedded networked sensors, pages 78-82. ACM New York, NY, USA, 2007

[9] Helen Fornazier et al., "Wireless Communication: Wi-Fi, Bluetooth, IEEE 802.15.4, DASH7”, ROSE 2012 ELECINF344 / ELECINF381, Télécom ParisTech, web site: http://rose.eu.org/2012/category/admin

[10] Jin-Shyan Lee et al., "A Comparative Study of Wireless Protocols: Bluetooth, UWB, ZigBee", and Wi-Fi, The 33rd Annual Conference of the IEEE Industrial Electronics Society (IECON), Taipei, Taiwan, November 5-8, 2007

[11] Klaus Gravogl et al., "Choosing the best wireless protocol for typical applications", 2nd Workshop on Ultra-low Power Wireless Sensor Networks (WUPS 2011) February

2011, Como, Italy, http://geodes.ict.tuwien.ac.at/PowerSavingHandbook/

[12] Z. Mammeri, “Réseaux sans fils Caractéristiques et principaux standards ”, M1 Info Cours de Réseaux, IRIT, Université Paul Sabatier, Toulouse http://www.irit.fr/ Zoubir.Mammeri/Chap WLAN.pdf

[13] Ghobad Heidari, "WiMedia UWB: Technology of Choice for Wireless USB and Bluetooth", edition John Wiley \& Sons Ltd 2008, ISBN 978- 11-470-51814-2 (HB)

[14] Ms. Dharmistha, D. Vishwakarma, "IEEE 802.15.4 and ZigBee: A Conceptual Study", International Journal of Advanced Research in Computer and Communication Engineering, ISSN: 2278 - 1021, Vol. 1, Issue 7, September 2012

[15] Vaddina Prakash Rao, “The simulative Investigation of Zigbee/IEEE 802.15.4”, Master Thesis of Science, DRESDEN UNIVERSITY OF TECHNOLOGY, FACULTY OF ELECTRICAL ENGINEERING AND INFORMATION TECHNOLOGY, Department of Electrical Engineering and Information Technology, Chair of Telecommunications, September, 2005 
[16] http://www.zigbee.org/Specifications/ZigBeeIP/Overview.aspx

[17] Reen-Cheng Wang et al., "Internetworking Between ZigBee/802.15.4 and IPv/802.3 Network", ACM 978-1-59593-790-2/07/0008, IPv '07, August 31, 2007, Kyoto, Japan.

[18] Rohan Tabish, Adel Ben Mnaouer, Farid Touati and Abdulaziz M. Ghaleb "A Comparative Analysis of BLE and IEEE802.15.4 (6LoWPAN) For U-HealthCare Applications"

Conference: Conference: IEEE GCC, At Doha, Qatar

[19] Farid Touati \& Rohan Tabish "U-Healthcare System: State-of-the-Art Review and Challenges" JMed Syst (2013) 37:9949 DOI 10.1007/s10916-013-9949-0

[20] d. Taslim Arefin, Mohammad Hanif Ali, A.K.M. Fazlul Haque "A Comparative Analysis of Short Range Wireless Protocols For Wireless Sensor Network" International Journal of Scientific \& Engineering Research, Volume 8, Issue 4, April-2017 840 ISSN 2229-5518

[21] I. Berdai «Étude Comparative Des Protocoles Zigbee Pro ET Zigbee Ip » University Of Quebec in Montreal, Memory, October 2016

[22] H. A. A.Al-Kashoasha and Andrew H.Kemp "Comparison of 6lowpan and Lpwan for the Internet of Things" Australian Journal of Electrical and Electronics Engineering, 2017https://Doi.Org/10.1080/1448837x.2017.1409920 